\title{
Feasibility study of high volume slag as cement replacement for sustainable structural lightweight oil palm shell concrete
}

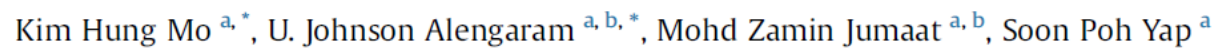 \\ a Department of Civil Engineering, Faculty of Engineering, University of Malaya, 50603 Kuala Lumpur, Malaysia \\ ${ }^{\mathrm{b}}$ Centre for Innovative Construction Technology (CCT), Department of Civil Engineering, University of Malaya, 50603 Kuala Lumpur, Malaysia
}

\section{A R T I C L E I N F O}

\section{Article history:}

Received 15 July 2014

Received in revised form

24 October 2014

Accepted 4 December 2014

Available online 11 December 2014

\section{Keywords:}

Sustainabl

Sustain

Oil palm shell

Lightweight concrete

Bond

Bond
Flexure

\begin{abstract}
A B S T R A C T
This paper presents a study on the use of high volume slag as a cement replacement material, and waste oil palm shell (OPS) as a lightweight aggregate to produce a sustainable lightweight concrete (LWC). In order to establish the feasibility of such concrete for structural purposes, the first part of the paper deals with the investigation of the mechanical and bond properties of OPS concrete (OPSC) with varying slag content. The results showed that even though an increase in the slag content led to the reduction in the strength, the OPSC with slag as a $60 \%$ cement replacement material exhibited compressive and splitting tensile strengths of 25 and $2.3 \mathrm{MPa}$, respectively, which exceeded the minimum stipulated strength required for structural LWC. In addition, the use of $60 \%$ slag in OPSC showed significant benefits in terms of the reduced cement consumption with improvement in the strength efficiency by almost 2 -fold compared to that without slag. On the other hand, it was found that the slag content, albeit as high as a $60 \%$ cement replacement level, did not show any significant adverse effects on the normalized bond strength, failure mode, bond strength-slip curve and slip at the ultimate bond strength of the OPSC. To further justify the suitability of the OSPC for structural application, the second part of the paper focuses on the experimental investigation of the flexural behaviour of the actual full-scale reinforced concrete beams. From the flexural tests, it was observed that there were no negative effects on the ultimate moment capacity, failure mode and moment-deflection behaviour of the reinforced concrete beams upon cement replacement with up to $60 \%$ slag. Therefore, the utilization of high volume slag-lightweight OPSC could be recommended for actual structural purposes.
\end{abstract}

() 2014 Elsevier Ltd. All rights reserved.

\section{Introduction}

Owing to the ever-present construction activities around the world, one of the most worrying environmental concerns pertains to the high amount of carbon dioxide $\left(\mathrm{CO}_{2}\right)$ emissions due to the use of cement. Approximately $1 \mathrm{t}$ of $\mathrm{CO}_{2}$ is released from the manufacture of $1 \mathrm{t}$ of cement. The cement industry alone contributes to approximately $5-7 \%$ of the world's $\mathrm{CO}_{2}$ emission. The increasing demand for cement due to the rapid growth in the construction industry could further increase this figure. It is expected that by 2020 , the global demand for cement would increase

Abbreviations: $\mathrm{CO}_{2}$, Carbon dioxide; LVDT, linear voltage displacement transducer; LWC, lightweight concrete; ODD, oven dry density; OPC, Ordinary Portlan cement; OPS, oil palm shell; OPSC, oil palm shell concrete; SP, superplasticiser. * Corresponding authors. Department of Civil Engineering, Faculty of Engineering, University of Malaya, 50603 Kuala Lumpur, Malaysia. Tel.: +60 379677632.

E-mail addresses: khmo890815@gmail.com (K.H. Mo), johnson@um.edu.my (U. Johnson Alengaram) by about $115-180 \%$ compared to the 1990 s, and this is likely to surge to $400 \%$ by 2050 (Damtoft et al., 2008). Therefore, there is a need to seek alternatives to partially replace the cement to reduce the adverse effects of the excessive usage of cement. One of the ways is through the use of mineral admixtures. Some of the more commonly available mineral admixtures include silica fume, fly ash and slag. The use of slag to partially replace cement is generally well accepted in the cement industry due to its low cost and reasonable strength even at high replacement levels. Furthermore, the use of slag provides additional environmental advantages, which include natural resource conservation and the recycling of industrial byproducts (Yang et al., 2014), since slag occurs as a by-product from the iron industry. Based on a study in China in 2012, the output of pig iron of more than 650 mil t produced around $200 \mathrm{mil} \mathrm{t}$ of blast furnace slag (Sun et al., 2014). The durability of concrete, particularly its resistance to chloride penetration, could be significantly improved with the use of slag, as this permits a longer corrosion-free service life of reinforced concrete structures under the most extreme natural environments (Bijen, 1996). Concrete 
with longer service life require less demolition and renovation works, which could effectively reduce greenhouse gas emissions and global warming index (Valipour et al., 2014). Based on the benefits of using slag as a cement replacement material, researchers in the past (Shafigh et al., 2013b; Mo et al., 2014b) had experimented with the use of ground granulated blast furnace slag in lightweight oil palm shell concrete (OPSC) to develop a more sustainable concrete.

In Malaysia, large amounts of waste oil palm shell (OPS), which occurs as a by-product from the palm oil extraction process, is dumped and stockpiled in the vicinity of factories. In 2011, oil palm plantation in the country covered about 4.98 million ha, which is approximately $15 \%$ of the land area in the country. Furthermore, based on the past 25 years of statistics, an increase in the plantation area by about 0.14 million ha/y and coupled with the growing demand for palm oil (Hansen et al., 2014), the industrial waste of OPS is expected to be in abundance in the future. As time passes, this growing amount of OPS dumped causes land pollution and creates an unwelcoming sight. The utilization of such waste, OPS, as a lightweight aggregate for the production of lightweight concrete (LWC), may ease these environmental concerns, and, at the same time, reduce the dependency on natural coarse aggregate, such as granite. Furthermore, the sourcing of locally available OPS for concrete could also lower the embodied energy associated with construction materials due to the reduction of imported materials (Stephan and Stephan, 2014), particularly conventional manufactured lightweight aggregates, which are not readily available in the country. Therefore, the combined usage of OPS and slag to reduce granite extraction and $\mathrm{CO}_{2}$ emission could therefore produce a desired sustainable 'green' lightweight concrete.

It was found that there was a reduction of about $50 \%$ in the overall $\mathrm{CO}_{2}$ emission for the production of a unit compressive strength of the OPSC when the amount of slag, as a partial cement replacement, was increased up to 70\% (Mo et al., 2014a). As reported by Shafigh et al. (2013b) and Mo et al. (2014a), although increasing the amount of slag in the OPSC could lead to a reduction in the compressive strength, the replacement level, as high as $70 \%$ could still produce a structural grade LWC. Such findings encourage further investigations concerning the use of OPSC with a high volume slag for structural application. Past research works mainly focused on the investigation of the mechanical properties; however, this is not sufficient to ascertain the structural feasibility of such concrete as one of the most important properties is the bond characteristic.

Although the bond properties are essential for the performance of the structural members, the effect of the mineral admixture on the bond between the concrete and the reinforcing bar was not given much attention in the past. Studies that were conducted mainly focused on the effects of silica fume (Hwang et al., 1994; Karatas et al., 2010) and fly ash (Hossain and Lachemi, 2008; Arezoumandi et al., 2013) on the bond strength of concrete, whereas very limited information is available for the effects of slag on the bond properties of concrete. Furthermore, some of these reports present contrasting findings and uncertainty still exists over the effect of the mineral admixture on the bond properties. Also, although preliminary studies on the bond capacities of plain OPSC were carried out in the past (Teo et al., 2007; Alengaram et al, 2010), the full bond behaviour was not investigated and very little information is available on the effect of high volume cement replacement on the bond behaviour of OPSC. Therefore, the first part of the study is devoted to investigating the effects of slag as a partial cement replacement on the bond properties of lightweight OPSC. This investigation focuses on three different levels of cement replacement with slag, specifically, $0 \%, 20 \%$ and $60 \%$. This is particularly important, especially in the case of the OPSC with $60 \%$ slag since replacing the majority of the traditional cement could significantly affect the concrete properties. Proper knowledge on the effects of slag on the bond properties in OPSC could provide the necessary guidance for designers involved with such concrete, and further enhance the feasibility of sustainable 'green' concrete for actual structural applications.

Past investigations have shown that despite the reduction in the strength of the OPSC or other types of LWC upon a high volume of cement replacement, the concrete could attain sufficient strength for structural purposes. However, in the past, there was no actua test or investigation carried out to evaluate the flexural performance of reinforced OPSC beams containing high amount of cement replacement for structural application. Intuitively, it would be expected that the cement replacement would not affect the flexural behaviour or the reinforced concrete beam significantly; however, it is important to bear in mind that when a higher reinforcement ratio is used, concrete with a significantly low strength could result in a reduced ultimate moment capacity as well as brittle failure due to the over-reinforced section of structura members. The brittle failure mode of over-reinforced concrete structures will undeniably be catastrophic. Therefore, in order to establish the feasibility of OPSC with high volume slag for structura purposes, using controlled strength grade 30 OPSC with varying slag content of $0 \%, 20 \%$ and $60 \%$, the second part of this study deals with the experimental investigation of the flexural behaviours of these full-scale reinforced lightweight OPSC beams with a fixed tensile reinforcement ratio of $1.0 \%$

\section{Experimental programme}

\subsection{Materials}

The slag used in the current study is ground granulated blast furnace slag, which is obtained from the steel-making process when molten iron slag is quenched from a blast furnace in water to form granules and ground to a specified fineness by using a grinding mill. The specific gravity of the ground granulated blas furnace slag used in this study was 2.90 compared to the specific gravity of 3.10 for Ordinary Portland cement (OPC). The chemical compositions of OPC and slag are listed in Table 1.

The coarse aggregate used was crushed OPS (specific gravity: 1.35) ranging in size between 2.36 and $9 \mathrm{~mm}$ (medium coarse gradation), and conforming to the specification of structural lightweight aggregates according to ACI 213R. The OPS was collected from a local palm oil factory and washed with detergent to remove the oil coating on the surfaces. Prior to casting, the OPS was soaked in water for $24 \mathrm{~h}$ before being air-dried to achieve a saturated surface dry condition. The OPS had bulk density of $658 \mathrm{~kg} / \mathrm{m}^{3}$ and 24-h water absorption value of $25 \%$.

Manufactured sand, which is obtained from the processing of crushed granite aggregate, is chosen to be used as the fine aggregate in this study instead of the conventional river sand. The manufactured sand provides a better environmentally friendly alternative since the excavation of natural sand can be avoided. The excessive excavation and use of natural river sand could lead to numerous environmental issues such as soil erosion, poor wate

Table

Chemical composition of cement and slag.

\begin{tabular}{lccccccccc}
\hline $\begin{array}{l}\text { Chemical } \\
\text { composition (\%) }\end{array}$ & $\mathrm{SiO}_{2}$ & $\mathrm{Fe}_{2} \mathrm{O}_{3}$ & $\mathrm{CaO}$ & $\mathrm{Na}_{2} \mathrm{O}$ & $\mathrm{Al}_{2} \mathrm{O}_{3}$ & $\mathrm{SO}_{3}$ & $\mathrm{~K}_{2} \mathrm{O}$ & $\mathrm{MgO}$ & $\mathrm{LOI}$ \\
\hline $\begin{array}{l}\text { Cement } \\
\text { Slag }\end{array}$ & 19.80 & 3.10 & 63.40 & 0.19 & 5.10 & 2.40 & 1.00 & 2.50 & 1.80 \\
\hline
\end{tabular}


quality, loss of natural habitats, flooding etc. On the other hand, the manufactured sand is a by-product obtained from crushing of granite for coarse aggregates. Although the process of crushing granite to produce manufactured sand requires more energy compared to excavation of sand (Flower and Sanjayan, 2007), the use of manufactured sand would be beneficial in the long run considering that virgin aggregate deposits are fast depleting in many areas; further, procurement of natural river sand in undeveloped rural areas would therefore result in higher emission of carbon dioxide to the environment due to the transportation of machineries and river sand over longer distances. Furthermore, the use of manufactured sand also guarantees higher quality control compared to natural river sand, which might contain a varying amount of impurities depending on the source. In addition, previous research (Nanthagopalam and Santhanam, 2011) reported that the use of manufactured sand is a viable alternative to fully replace conventional river sand for the production of concrete as no significant adverse effects on the strength of the concrete were observed with the use of manufactured sand. In this study, manufactured sand with a specific gravity of 2.56 and size between 0.3 and $5 \mathrm{~mm}$ was used.

Potable water that was free from contaminants and impurities was used as mixing water in the casting. A polycarboxylate-ether based superplasticiser (SP) was added to facilitate workability. A grade $500 \mathrm{MPa}$ high yield ribbed steel reinforcing bar with a diameter of $12 \mathrm{~mm}$ was used for the bond test.

\subsection{Mix proportion and procedure}

As shown in Table 2, a total of three concrete mixes with constant binder, sand, OPS and water content were prepared for this study while the variable investigated was the varying levels of cement replacement with slag, specifically, $0 \%, 20 \%$ and $60 \%$. The SP content was fixed at $1.0 \%$ by the mass of the binder for all mixes. Based on the mix design used in this study where the OPS content is $400 \mathrm{~kg} / \mathrm{m}^{3}$ and assuming $65 \mathrm{~m}^{2}$ of concrete is required for a unit of double storey terrace house, the amount of waste OPS available annually, which is about 4 million t in 2006 (Teo et al., 2007), could produce OPSC that would be sufficient for the construction of almost 150,000 units of double storey terrace houses in the country.

In the mixing process, the OPS and manufactured sand were dry mixed for $3 \mathrm{~min}$, followed by the addition of OPC and slag, and mixed for a further $6 \mathrm{~min}$. Thereafter, half of the required water was added and mixed for 3 min before the remainder of the water and SP were added. The entire wet mixing lasted for $10 \mathrm{~min}$ before being poured into oiled moulds and vibrated. All the specimens except for the beams were de-moulded after $24 \mathrm{~h}$ and then water cured for $28 \mathrm{~d}$. The beams were kept in the mould and water cured for $7 \mathrm{~d}$ before being de-moulded. The beams were continuously cured with water until the age of $28 \mathrm{~d}$, after which, all specimens were air-cured until age of testing.

\subsection{Test method}

\subsubsection{Mechanical properties test}

The $100 \mathrm{~mm}$ cube specimens were tested for compressive strength (BS EN 12390-3: 2002) whereas cylindrical specimens

Table 2

Mix proportion.

\begin{tabular}{llclll}
\hline Mix & $\begin{array}{l}\text { Cement } \\
\left(\mathrm{kg} / \mathrm{m}^{3}\right)\end{array}$ & $\begin{array}{l}\text { Slag } \\
\left(\mathrm{kg} / \mathrm{m}^{3}\right)\end{array}$ & $\begin{array}{l}\text { Sand } \\
\left(\mathrm{kg} / \mathrm{m}^{3}\right)\end{array}$ & $\begin{array}{l}\text { OPS } \\
\left(\mathrm{kg} / \mathrm{m}^{3}\right)\end{array}$ & $\begin{array}{l}\text { Water } \\
\left(\mathrm{kg} / \mathrm{m}^{3}\right)\end{array}$ \\
\hline S0 & 520 & 0 & 940 & 400 & 170 \\
S20 & 416 & 104 & 940 & 400 & 170 \\
S60 & 208 & 312 & 940 & 400 & 170 \\
\hline
\end{tabular}

with dimension of $100 \mathrm{~mm} \emptyset \times 200 \mathrm{~mm}$ height were tested for splitting tensile strength (BS EN 12390-6: 2000). A total of three specimens were tested for each mix and the average of the three values was reported. All specimens were tested at the age of $180 \mathrm{~d}$.

\subsubsection{Bond test}

For the bond test, a concrete prism specimen measuring $200 \times 200 \times 350 \mathrm{~mm}^{3}$ with an embedded reinforcing steel bar was used. As shown in Fig. 1, the bonded length was fixed at 4 times the diameter of the reinforcing bar $(48 \mathrm{~mm})$ at the centre of the embedded steel bar. A PVC tube sleeve was used in the un-bonded length to ensure smooth contact between the steel bar and the concrete. The protruding steel reinforcing bar was gripped and concentric pull-out force was applied via a displacement-controlled Universal Testing Machine. The slip of the steel reinforcing bar relative to the concrete was measured through the use of four linear voltage displacement transducers (LVDT). The average readings from the four LVDTs were taken as the value of the slip. During testing, the pull-out load from the Universal Testing Machine and the displacement measurements from the LVDTs were recorded continuously at intervals of $1 \mathrm{~s}$ using a data logger. A total of two specimens were tested for each mix at the age of $180 \mathrm{~d}$.

\subsubsection{Flexural test}

The cross section of the beam is shown in Fig. 2. The dimensions of the beam were $150 \mathrm{~mm}$ (width) and $300 \mathrm{~mm}$ (height), with a clear cover of $25 \mathrm{~mm}$. All beams were designed as under-reinforced to ensure flexural failure with $4 \times 12 \mathrm{~mm}$ diameter steel reinforcing bars as tension reinforcement and $2 \times 10 \mathrm{~mm}$ diameter steel reinforcing bars as compression reinforcement. Mild steel links of $6 \mathrm{~mm}$ diameters were provided at $75 \mathrm{~mm} \mathrm{c} / \mathrm{c}$ as shear reinforcement at the shear span. The beams cast were $3300 \mathrm{~mm}$ in length and had a clear span of $3000 \mathrm{~mm}$. All the reinforced concrete beams were tested under two point loads; the load was transferred from the actuator of an INSTRON machine with $250 \mathrm{kN}$ capacity via a spreader beam. The distance between the two point loads was fixed at $1000 \mathrm{~mm}$ for all the beams (Fig. 3). The flexural testing was conducted under load-controlled rate at $10 \mathrm{kN} / \mathrm{min}$ followed by a

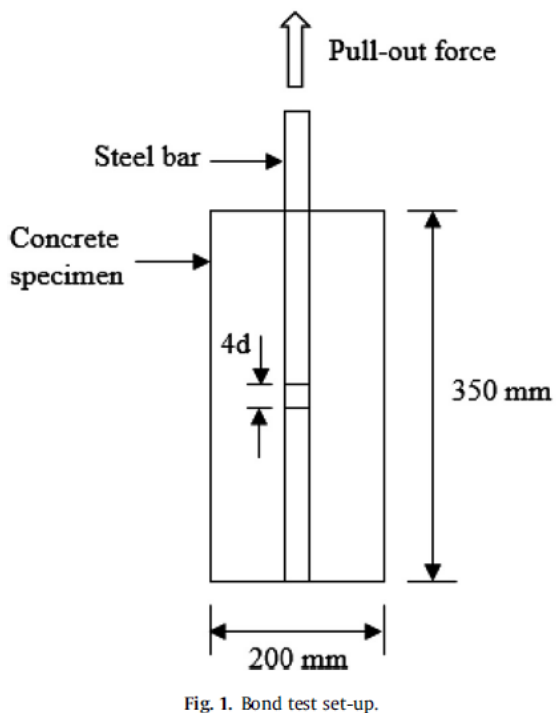




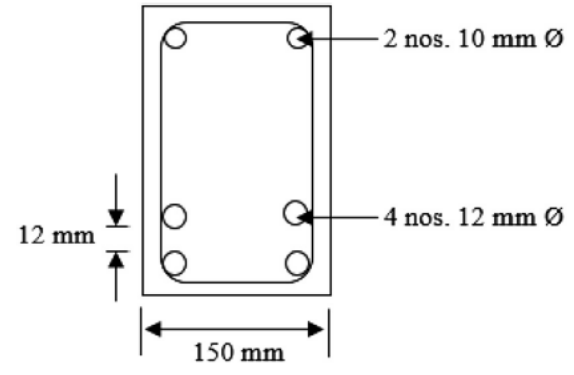

Fig. 2. Beam details.

displacement-controlled rate of $2 \mathrm{~mm} / \mathrm{min}$. The mid-span deflection of the beam was measured through the use of a LVDT connected to a data logger.

\section{Results and discussion}

\subsection{Oven dry density}

The oven dry density (ODD) of OPSC was obtained by drying the concrete specimens in an oven with a temperature of $105 \pm 5^{\circ} \mathrm{C}$ for $48 \mathrm{~h}$. The ODD obtained in this study are presented in Table 3. It was found that all mixes had an ODD of below $2000 \mathrm{~kg} / \mathrm{m}^{3}$ and, thus, the OPSC produced in this study could be categorized as LWC according to EN206-1. The ODD of all mixes obtained had a standard deviation of less than $20 \mathrm{~kg} / \mathrm{m}^{3}$, which gave a good confidence limit in the results obtained. The ODD of the OPSC obtained was generally about $20-30 \%$ lower compared to conventional concrete. The significant reduction in the density of the concrete reduces the dead load of the structural members, and, thus, this allows for flexibility in the structural design, such as increased span length, reduced depth of members and amount of reinforcement. The trend of decreasing the ODD with the increased amount of slag used in the OPSC observed in this study also confirmed the reported findings in previous research (Shafigh et al., 2013b), which was due to the lower specific gravity of the slag (Akcaozoglu and Atis, 2011).

\subsection{Compressive strength}

The compressive strength was found to decrease with the increased replacement of cement by slag; as shown in Table 3, the compressive strength reduced from $33.3 \mathrm{MPa}$ to $30.8 \mathrm{MPa}$ when the slag replacement level was $20 \%$ and this was further reduced to $25.4 \mathrm{MPa}$ when the slag replacement level was increased to $60 \%$ This observation agrees well with previous research in that the increased slag content led to a reduction in the compressive
Table 3

Oven dry density, compressive strength and splitting tensile strength

\begin{tabular}{|c|c|c|c|c|c|c|}
\hline \multirow[t]{2}{*}{ Mix } & \multicolumn{2}{|c|}{$\begin{array}{l}\text { Oven dry } \\
\text { density }\left(\mathrm{kg} / \mathrm{m}^{3}\right)\end{array}$} & \multicolumn{2}{|c|}{$\begin{array}{l}\text { Compressive } \\
\text { strength (MPa) }\end{array}$} & \multicolumn{2}{|c|}{$\begin{array}{l}\text { Splitting tensile } \\
\text { strength (MPa) }\end{array}$} \\
\hline & Mean & S.D. & Mean & S.D. & Mean & S.D. \\
\hline So & 1937 & 13 & 33.30 & 1.36 & 2.690 & 0.016 \\
\hline S20 & 1903 & 12 & 30.77 & 1.13 & 2.529 & 0.071 \\
\hline S60 & 1851 & 17 & 25.40 & 1.24 & 2.328 & 0.101 \\
\hline
\end{tabular}

strength in the OPSC (Mo et al., 2014a). Nevertheless, all of the mixes exceeded the minimum requirement of compressive strength for structural grade lightweight concrete as per ACI 213R. Furthermore, the reduction in compressive strength of about $23 \%$ upon $60 \%$ cement replacement with slag was lower compared to the use of $50 \%$ fly ash, which caused a decrease in the compressive strength of about 30\% in the OPSC (Shafigh et al.,2013a). This implies that the use of slag is preferable compared to fly ash with regard to the high level of cement replacement in the concrete.

Although the use of slag as a cement replacement in OPSC led to a reduction in compressive strength, in terms of environmental consideration, it is appropriate to analyse the effect of cement consumption along with the resultant strength of concrete. Therefore, the compressive strength efficiency is used as a performance index for the purpose of this investigation. The compressive strength efficiency is defined as a unit compressive strength per kilogram cubic metre of cement used and denoted as $\mathrm{MPa} / \mathrm{kgm}^{-3}$ (Chao-Lung et al., 2011). Pelisser et al. (2012) also utilized a similar performance index of $\mathrm{kg} / \mathrm{MPa}$, albeit in an inverse relationship, to evaluate the performance of LWC in this aspect. OPSC without any slag was previously reported (Shafigh et al., 2014) to have higher efficiency compared to conventional concrete and lightweight concrete made with expanded clay. In the present study, it was observed that the use of higher slag content in OPSC further increased the compressive strength efficiency. The compressive strength efficiency of $0.064,0.074$ and $0.122 \mathrm{MPa} / \mathrm{kg} \mathrm{m}^{-3}$ was found for the mixes S0, S20 and S60. It should be noted that from the present investigation, lightweight OPSC with a compressive strength of about $25 \mathrm{MPa}$ was achievable with the aid of a high volume slag content and significantly reduced the cement consumption to approximately $200 \mathrm{~kg} / \mathrm{m}^{3}$. The savings from the cement consumption through the use of slag as a partial cement replacement not only reduced the $\mathrm{CO}_{2}$ being emanated from the production of cement, the re-use of industrial by-products, such as slag, could significantly scale down the environmental problems caused by the disposal of these materials, such as water and air pollution. This is highlighted in a life cycle assessment carried out by Blankendaal et al. (2014) where it was reported that the use of slag could reduce the environmental impact to a maximum of $39 \%$. Similar savings in the embodied carbon emission of about $43 \%$ was also revealed by Rai et al. (2011) when slag was used at a $50 \%$ cement replacement level.

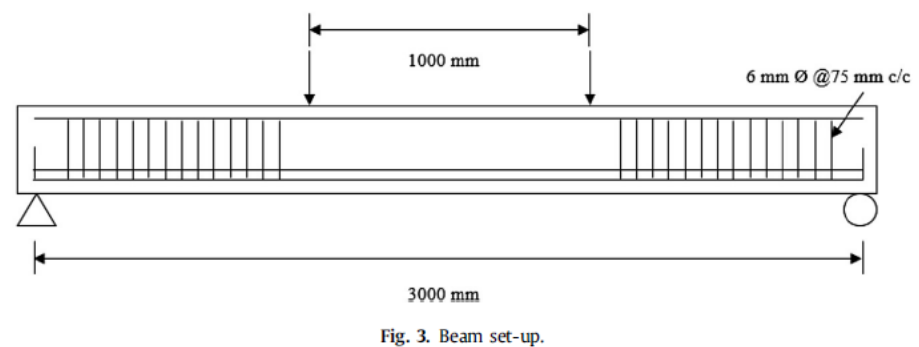




\subsection{Splitting tensile strength}

The splitting tensile strength for mixes S0, S20 and S60 obtained was 2.69, 2.53 and $2.33 \mathrm{MPa}$, respectively. The splitting tensile strengths were about $8 \%$ of the corresponding cube compressive strengths in this study and corresponded well to the previous findings for OPSC (Alengaram et al., 2013). As a function of the compressive strength, the splitting tensile strength also reduced with the increased replacement of cement with slag. Shafigh et al. (2010) reported that there is a direct relationship between the cube compressive strength to the power of two-thirds and the splitting tensile strength for OPSC, as shown in equation (1), while Gesoglu et al. (2004) also proposed a similar relationship but with a larger coefficient (equation (2)) for LWC made from cold-bonded fly ash aggregates. In this study, it was found that the splitting tensile strength of OPSC could be predicted using Equation (2) since only $3-5 \%$ of the difference was observed between the experimental and predicted values of the splitting tensile strength.

$$
\begin{aligned}
& \mathrm{f}_{\mathrm{t}}=0.20^{3} \sqrt{\mathrm{f}_{\mathrm{cu}}^{2}} \\
& \mathrm{f}_{\mathrm{t}}=0.27^{3} \sqrt{\mathrm{f}_{\mathrm{cu}}^{2}}
\end{aligned}
$$

where $f_{t}$ is the splitting tensile strength (MPa) and $f_{c u}$ is the corresponding cube compressive strength ( $\mathrm{MPa})$.

Although the increase in the slag replacement led to a reduced splitting tensile strength, the OPSC with a $60 \%$ slag replacement level still exhibited a splitting tensile strength exceeding 2.0 MPa; this is sufficient for the use of LWC in structural applications based on ASTM C330.

\subsection{Bond properties}

The knowledge of the bond is of significant importance since the bond between the steel reinforcing bar and the neighbouring concrete basically allows the reinforced concrete to function as a structural material. The transfer of forces from the reinforcing bar to the surrounding concrete occurs through three mechanisms, namely i) adhesion force between the reinforcing bar and the concrete, ii) frictional force, and iii) mechanical anchorage or bearing of reinforcing bar ribs against the concrete surface. An insufficient bond between the steel reinforcing bar and the concrete could lead to an excessive slip, which would result in a permanent deformation and the possibility of internal cracks (Mor, 1992), leading to a reduced load bearing capacity of structural members.

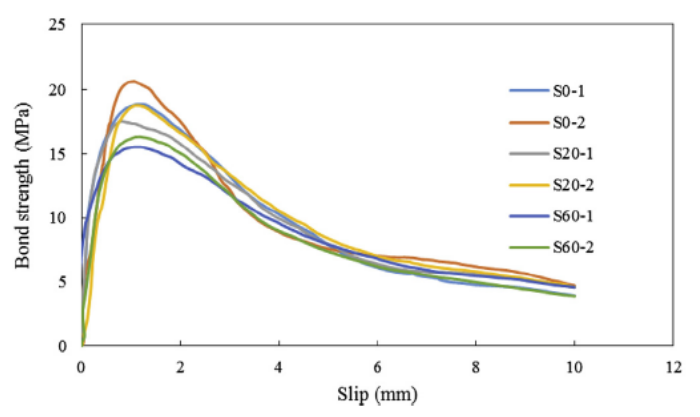

Fig. 4. Bond strength-slip relationship.
All specimens exhibited a pull-out mode failure in this study; this could also be reflected from the shape of the bond strength-slip graphs shown in Fig. 4. No significant difference was found from the shape of the bond strength-slip curve due to the amount of cement replacement with the slag. The bond strength is determined as follows:

$\mathrm{f}_{\text {be }}=\mathrm{P} /(\pi \times \emptyset \times \mathrm{L})$

where $f_{\text {be }}$ is the experimental bond strength (MPa), $P$ is the maximum pull-out load $(\mathrm{N}), \emptyset$ is the diameter of the steel reinforcing bar $(\mathrm{mm})$ and $\mathrm{L}$ is the bond length $(\mathrm{mm})$.

The results obtained for the bond strength and corresponding slip for all OPSC mixes are presented in Table 4. The bond strengths ranged between 15 and $19 \mathrm{MPa}$ for the OPSC; these values were significantly higher than those previously obtained by Teo et al. (2007) and Alengaram et al. (2010). This could be attributed to the different failure modes observed in that splitting failure instead of pull-out failure was observed in the case of the bond test carried out by Alengaram et al. (2010).

The highest ultimate bond strength was found for the mix S0 and the bond strength reduced with the increase of cement replacement with slag. Nevertheless, as shown in Table 4, the bond strengths obtained were about 5-7 times higher compared to the theoretical bond strength proposed in BS 8110 (equation (4)) and 3 times compared to that proposed in EN 1992 (equation (5)). Thus, it can be said that the theoretical bond strength proposed in BS 8110 is conservative in the case of OPSC. Although the increased cement replacement with slag reduced the ultimate bond strength, the mix, S60, with high volume slag content could still achieve sufficient bond strength for structural applications.

$\mathrm{f}_{\mathrm{bt}}=\beta \sqrt{\mathrm{f}_{\mathrm{cu}}}$

where $f_{b t}$ is the theoretical bond strength (MPa) and $\beta$ is the bond coefficient ( 0.50 is used for this study).

$f_{b t}=2.25 \eta_{1} \eta_{2} f_{t}$

where $\eta_{1}$ is the coefficient for the quality of the bond condition and position of the bar during concreting (1.0 is used for this study), and $\eta_{2}$ is the coefficient for the bar diameter (1.0 is used for this study).

A reduction of about $20 \%$ in the bond strength of OPSC was observed when $60 \%$ of slag content was used. As reported in Section 3.2 , the increased amount of slag reduced the strength of the OPSC. This could be due to the limited hydration of the slag caused by the use of the low water-to-binder ratio in the OPSC (Mo et al., 2014a). Hence, the resulting concrete could have a weaker bonding with the steel reinforcing bar, which could lead to poorer adhesion and reduced bond strength when the slag content was increased (Xia et al., 2006). Hwang et al. (1994) and Hamad and Itani (1998) also reasoned that the use of silica fume as a cement replacement caused a loss in the friction between the concrete and steel reinforcing bar, which subsequently, led to a lower bond strength. In addition, Turk et al. (2010) reported a bond strength decrease when fly ash was used at a replacement level of $30 \%$ in self-compacting concrete. However, when mineral admixtures were added (Corinaldesi and Moriconi, 2009), the bond strength was increased due to the improved pore structure of the concrete, which could facilitate improved bonding.

Therefore, to fully ascertain the effects of the mineral admixture on the bond strength of concrete, the effect of the compressive strength needs to be taken into account, and, thus, the values of the bond strength were normalized with the square root of the compressive strength to eliminate the variations in the

Link to Full-Text Articles :

http://www.sciencedirect.com/science/article/pii/S0959652614013109 